Routledge Global Popular Music Series
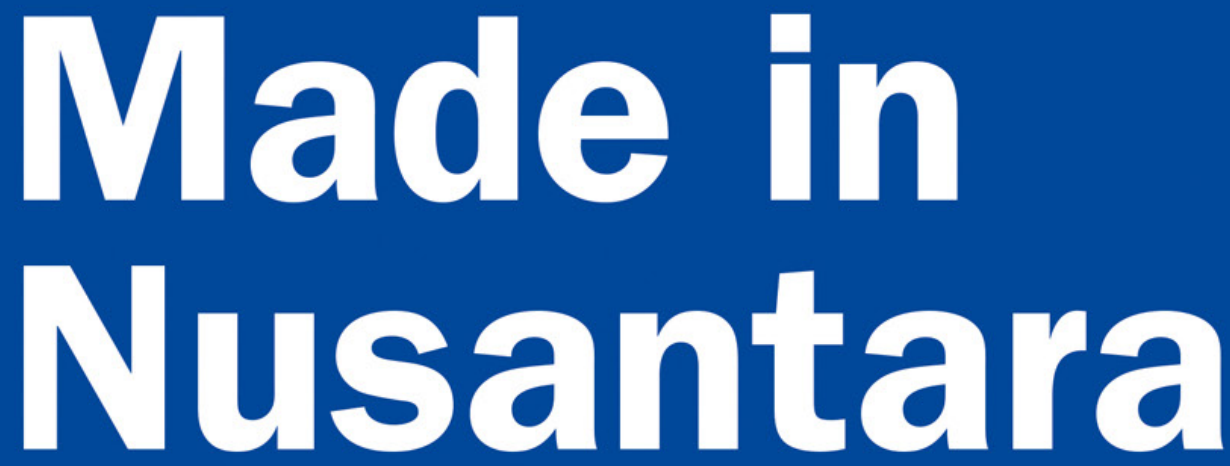

\title{
Studies in Popular Music
}

Edited by Adil Johan and Mayco A. Santaella 


\section{Made in Nusantara}

Made in Nusantara serves as a comprehensive introduction to the history, sociology, ethnography, and musicology of historical and contemporary popular music in maritime Southeast Asia.

Each essay covers major figures, styles, and social contexts of genres of a popular nature in the Nusantara region including Malaysia, Indonesia, Brunei, Singapore, and the Philippines. Through a critical investigation of specific genres and their spaces of performance, production, and consumption, the volume is organised into four thematic areas: 1) issues in Nusantara popular music; 2) history; 3) artists and genres; and 4) national vs. local industries.

Written by scholars working in the region, Made in Nusantara brings local perspectives to the history and analysis of popular music and critically considers conceptualisations developed in the West, rendering it an intriguing read for students and scholars of popular and global music.

Adil Johan is a research fellow at the Institute of Ethnic Studies (KITA), Universiti Kebangsaan Malaysia.

Mayco A. Santaella is an associate professor and head of the Film and Performing Arts Department at Sunway University, Malaysia. 


\title{
More than Mimicry \\ Alternative Modernities in the Birth and Development of Iban Popular Music
}

\author{
Connie Lim Keh Nie
}

This chapter provides a critical overview of the birth and development of Iban popular music in Sarawak from the 1950s to the 1970s. It examines the potential of popular music historiography to uncover paradoxes of modernity in the socio-cultural meanings of song lyrics of the Iban who are the largest indigenous ethnic group in Sarawak. During this pivotal period in Malaysian history, the Iban experienced modernity in flux through the agents of change from Brooke's rule to British colonialism to the Federation of Malaysia. Inspired by Barendregt's (2014) "alternative conceptions of modernity" in Southeast Asian popular music, this chapter traces the historical introductions of Western music in Sarawak from the Brooke Dynasty, the establishment of Iban Radio under Radio Sarawak during the British colonial era, and the development of the Iban recording industry in the late 1960s during the formation of the Malaysian nation-state. These introductions reveal that Iban popular music did not just imitate pop culture but commandeered it as a platform for pre-modern warrior identity, nation-state promotion, and proclaiming pride in regional Sarawakian identity.

Song lyrics, as core discourse, reveal a poetic narrative to the socio-cultural, the sociopolitical, as well as the dynamic movements of Iban people. Iban radio broadcasts not only served to disseminate information about the new nation, but also emphasised "the importance of Iban language" and the preservation of the uniqueness of a "reinvented cultural heritage" (Postill 2008, 214). Indeed, the emergence of the radio station broadened the Iban's exposure to adapt and assimilate popular music styles. The rise of Radio Sarawak in 1954 played an important role in disseminating information to the Iban and it also had become one of the most important platforms where Iban popular songs were created as a response towards modernity. In this chapter, I argue that at the same time Iban acquired popular music skills, they also used music as a medium to portray Iban culture, identity, and ethnicity within the larger nation-state where Malay and Western cultures dominated. Through a history of Iban radio and a lyrical analysis of Iban songs, this chapter interrogates the socio-cultural and socio-political factors that contributed to the creation of these Iban pop songs. The analysis pays close attention to meanings embedded in the lyrics that do not simply mimic popular culture but contain deeply rooted, pre-modern elements of identity such as sentiments towards modernity and nation-building, proclaiming Sarawak as a state within the Federation of Malaysia. 